\title{
Newborn colonization and antibiotic susceptibility patterns of Streptococcus agalactiae at the University of Gondar Referral Hospital, Northwest Ethiopia
}

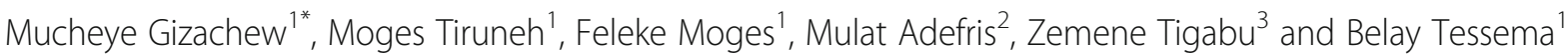

\begin{abstract}
Background: Group B Streptococcus (GBS) that asymptomatically colonizing the recto-vaginal area of women is the most important cause of neonatal colonization. There is paucity of evidence about newborn colonization with GBS in Ethiopia. Thus, this study was aimed to determine the prevalence of newborn colonization with GBS, antibiotic susceptibility patterns of the isolates and associated risk factors at the University of Gondar Referral Hospital in Northwest Ethiopia
\end{abstract}

Methods: A prospective cross sectional study was conducted from December 2016 to November 2017. A total of 1,155 swabs from nasal, ear and umbilical areas of the newborns were collected from the 385 newborns. Identifications of the isolates and antibiotic susceptibility testing were done by using conventional methods.

Results: Sixty two (16.1\%, 95\% Cl: 12.2\% - 20\%) of the newborns were colonized by GBS. Seven percent of the total specimens were positive for GBS. The antibiotics susceptibility rates of GBS (average of the three body sites tested) were $95.1 \%, 89.6 \%, 88.9 \%, 85.7 \%, 85.3 \%, 81.3 \%, 76.9 \%, 76.1 \%, 73.8 \%$, and $34.4 \%$ to ampicillin, penicillin, ciprofloxacin, chloramphenicol, vancomycin, azitromycin, erythromycin, clindamycin, ceftriaxone, and tetracycline, respectively. A multilogistic regression analyses were shown that the newborns that were from mothers whose education status was below tertiary level, and newborns from mothers who were: being employed, being nullipara and multigravida were at risk for colonization with GBS.

Conclusion: Prevalence of neonatal colonization with GBS was higher than it was reported in three decades ago in Ethiopia. Ciprofloxacin, chloramphenicol, vancomycin and azithromycin were identified as the drug of choice next to ampicillin and penicillin.

Keywords: Antibiotic susceptibility pattern, Colonization, Group B Streptococcus, Newborns

\section{Background}

The 2016 Ethiopian Demographic and Health Survey (EDHS) indicates that the overall mortality rate of under five children is $67 / 1000$ live births, with the infant mortality rate of $48 \%$ ( $29 \%$ neonatal and $19 \%$ post-neonatal) deaths/1,000 live births. The estimate of child mortality is 20 deaths/1000 children surviving to 12 months of age

\footnotetext{
* Correspondence: muchegiza@gmail.com

${ }^{1}$ Department of Medical Microbiology, School of Biomedical and Laboratory Sciences, College of Medicine and Health Sciences, University of Gondar, P. O. Box 196, Gondar, Ethiopia

Full list of author information is available at the end of the article
}

[1]. Women in the Amhara National Regional State have the fertility rate of 4.2 , and infant and maternal mortality rates of 76/1000 live births and 676/100,000, respectively [2]. Asymptomatic Streptococcus agalactiae (Group B Streptococcus, GBS) recto-vaginal colonization of women is assumed to be one of the contributing factors. It is the most significant pathogen, although little is known about its epidemiology and risk in resource limited countries [3]. Since neonatal infections cause a significant proportion of deaths in the first week of life, more data are needed about the burden of neonatal colonization [4].

(c) The Author(s). 2018 Open Access This article is distributed under the terms of the Creative Commons Attribution 4.0 International License (http://creativecommons.org/licenses/by/4.0/), which permits unrestricted use, distribution, and 
Since 1960s, GBS has been identified as a major public health problem that causes perinatal morbidity and mortality. It also became the most prevalent causes of fatal infections in newborns [5-7]. The researchers estimated about 410,000 GBS cases and 147,000 stillbirths and infant deaths are estimated to occur every year. Despite containing $13 \%$ of the world's population, Africa had the highest burden with $54 \%$ cases and $65 \%$ of stillbirths and infant deaths [8]. GBS causes sepsis, pneumonia, and meningitis in neonates; bacteraemia, amnionitis, endometritis, and urinary tract infection in pregnant women [9-11]. The Global prevalence of GBS neonatal colonization rate ranged from $1.6 \%$ in Turkey [12] to $52.9 \%$ in Pakistan [13], and South Africa took the lion share among few African reports [14]. However, evidence on GBS colonization rate of newborns largely remains sparse in the African setting, particularly in Ethiopia.

Furthermore, provision of empiric treatment brings up antibiotic resistance and stewardship issues [8]. Reports from different countries revealed the reduced susceptibility to penicillin, and the increased rate of macrolide resistance GBS isolates for the last few decades [15]. A 2005-2007 Surveillance in Argentina showed the presence of GBS isolates resistance (in minimum inhibitory concentration; MIC range $\mu \mathrm{g} / \mathrm{L}$ ) to ciprofloxacin (32-64 $\mu \mathrm{g} / \mathrm{L})$, levofloxacin $(16-32 \mu \mathrm{g} / \mathrm{L})$, ofloxacin $(32-64 \mu \mathrm{g} / \mathrm{L})$, and norfloxacin $(32-64 \mu \mathrm{g} / \mathrm{L})$, and all were susceptible to penicillin $(0.06 \mu \mathrm{g} / \mathrm{L})(16)$. Of the $1160 \mathrm{GBS}$ isolates in Australia, 6.4\% demonstrated erythromycin resistance and $4.2 \%$ to clindamycin [16]. Another study in USA revealed that all the neonatal GBS were susceptible to penicillin, vancomycin, chloramphenicol, and cefotaxime. Its resistance rates to erythromycin was $20.2 \%$, and $6.9 \%$ to clindamycin [17]. Another study in France revealed $38.2 \%$ erythromycin and $25.6 \%$ clindamycin resistance neonatal GBS [18]. However, as is the case in several other African countries, neonatal GBS colonization in Ethiopia has not been well documented. In addition, no preventive strategies for GBS infection have been yet formulated in the study area. Thus, this study was aimed to determine the prevalence of newborn colonization with GBS, its antibiotic susceptibility profile, and associated risk factors in University of Gondar referral hospital, Northwest Ethiopia.

\section{Methods}

\section{Study area}

The study was conducted at the University of Gondar Referral Hospital, Northwest Ethiopia. The University of Gondar Referral Hospital is one of the oldest hospitals located $737 \mathrm{~km}$ away from Addis Ababa, the Capital of Ethiopia with the Latitude of $12^{\circ} 31^{\prime} \mathrm{N}$, and Longitude $37^{\circ} 25^{`} \mathrm{E}$.. The Central Statistical Agency of Ethiopia population projection report and the Amhara National
Regional State Health Bureau report showed that the Amhara region has a population of 20,018,988, of which, $49.92 \%$ were females, and $15.62 \%$ of the total population was urban inhabitants. The hospital serves about five million people. It has 450 to 600 delivery admission services a month. No GBS screening and provision of intrapartum antibiotic prophylaxis for pregnant women established yet in the hospital.

\section{Study Design and Period}

A prospective cross-sectional study design was conducted between December 2016 and November 2017.

\section{Population \\ Source population}

All newborns who were delivered at the University of Gondar Referral Hospital in Northwest Ethiopia were the source population.

\section{Study population}

The study populations were those newborns delivered from pregnant women whose gestational age was $\geq 35$ weeks.

\section{Inclusion and exclusion criteria Inclusion criteria}

Newborns whose mothers not on antibiotics during delivery and those newborns who have been delivered vaginally at $\geq 35$ gestational weeks of pregnancy, and infants $\leq 30$ minutes were included in the study.

\section{Exclusion criteria}

Newborns whose mothers; did use vaginal cream, lubricants or traditional sterilizer (vinegar) in the last 10 days prior to giving birth; were in emergency room, severely ill, current vaginal bleeding, use of an intra-vaginal product in the past 24hours (douche, antifungal products), mentally unstable pregnant women; those who were in multiple birth and refusal for study participation from mothers or guardians were excluded.

\section{Sample size determination}

The sample size was calculated using the single population proportion estimation formula by taking $5 \%$ as the prevalence of neonatal GBS colonization [19].

$n=\frac{z_{\alpha / 2}^{2} \times p(1-P)}{d^{2}}$ Where; $n=$ sample size, $p=$ prevalence of neonatal colonization with GBS in Ethiopia ( $p=5 \%$ ), $\mathrm{d}=$ maximum allowable error (margin of error) $=0.05$, $Z=$ value of standard normal distribution (Z-statistic) at $95 \%$ confidence level $(z=1.96)$ and it became 73 newborns; however, to increase the precision/validity of the findings, the sample size was increased to 385 by taking $p=50 \%$. 
Variables

\section{Dependent variable}

Colonization of newborns with Group B Streptococcus (GBS), Antibiotic susceptibility patterns of GBS.

\section{Independent variables}

Maternal age, residence, education, and occupation, gestational age, parity, history of still birth, history of abortion, gravidity, antenatal care (ANC) visit, contraceptive use, history of preterm delivery, length of premature rupture of membrane (ROM), human immune deficiency virus (HIV) status, sex of newborn, Appearance, Pulse, Grimace, Activity, and Respiration (APGAR) score, history of neonatal death, newborn`s weight $(\mathrm{Kg})$, resuscitation required, Newborn to mother immediate close contact (baby with the mother soon following delivery or baby not in the neonatal intensive care unit), duration of labor (hours).

\section{Data collection, sampling technique and laboratory procedures}

Demographic and biological data were collected from the newborns immediately following birth pregnant women with $\geq 35$ gestational weeks of pregnancy by trained midwives at the maternity ward in the hospital until the pre-determined sample size was reached.

\section{Questionnaire}

A pre-tested questionnaire (Additional file 1) 5\% (20) was used to collect the data for the assessment of the study participants' (pregnant women with $\geq 35$ gestational weeks) demographic situations and to investigate the associated risk factors to newborn GBS colonization. Questionnaire were prepared in English using published studies with certain change and translated into the local language (Amharic). The response of each participant re-translated into English for analysis and report.

\section{Biological Specimen collection}

Three body surface site (nasal, umbilical and ear) swabs of newborns were collected and analyzed at the University of Gondar Microbiology Laboratory by using the recommended methods $[10,20]$.

\section{Swab culture}

Using the Centers for Disease Control and prevention (CDC) guidelines, nasal, umbilical and ear swabs were collected from each newborn and placed in the non nutritive Amies transport medium. Within 2 to 4 hours of collection, the swabs were placed in Todd-Hewitt selective enrichment broth supplemented with colistin $(10 \mu \mathrm{g} / \mathrm{ml})$ and naldixic acid $(15 \mu \mathrm{g} / \mathrm{mL})$ (Cart Roth $\mathrm{GmbH}+$ Co. KG-Schoemperlensrr. 3-5-D-76185 Karisruhe, Germany). The inoculated selective medium was incubated at $37{ }^{\circ} \mathrm{C}$ in $5 \% \mathrm{CO}_{2}$ for 24hours. The growth (turbidity) was sub-cultured in 5\% defibrinated sheep-blood agar and incubated for 24 hours at $37{ }^{\circ} \mathrm{C}$ in $5 \% \mathrm{CO}_{2}$ atmosphere. All suspected colonies (with narrow hemplysis) were sub-cultured on nutrient agar and subjected to gram stain and catalase test. All gram positive cocci and catalase negative isolates were tested for CAMP factor for presumptive identification.

\section{CAMP (Christie-Atkins-Munch-Petersen) test}

CAMP test was used to differentiate GBS (CAMP positive) from Streptococcus pyogene (beta-hemolytic CAMP negative) by inoculating the known Staphylococcus aureus onto 5\% defibrinated sheep blood agar down the center of the plate with a wire loop. Group B Streptococcus (test bacterium) was then streaked in a straight line perpendicular to the $S$. aureus within $2 \mathrm{~mm}$ far. The plate was then incubated at $35{ }^{\circ} \mathrm{C}$ for 24 hours. A positive CAMP result was indicated by an arrowhead-shaped enhanced zone of beta-hemolysis in the area between the test organism and $S$. aureus with the arrow-point towards the $S$. aureus streak. The CAMP test positive colonies were presumptively considered as GBS

\section{Antibiotic susceptibility testing of Group B Streptococcus}

Susceptibility of GBS isolates were tested against 10 antibiotics (Oxoid, Basingstoke, UK):penicillin G (P, $10 \mathrm{IU})$,

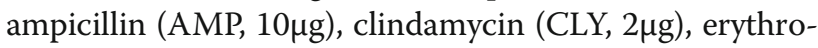
mycin $(\mathrm{E}, 15 \mu \mathrm{g})$, chloramphenicol $(\mathrm{C}, 30 \mu \mathrm{g})$, ciprofloxacin $(\mathrm{CIP}, 5 \mu \mathrm{g})$, ceftriaxone $(\mathrm{CRO}, 30 \mu \mathrm{g})$, vancomycin (VA, $30 \mu \mathrm{g})$, Azithromycin (AZM, $15 \mu \mathrm{g}$ ), and tetracycline (TE, $30 \mu \mathrm{g}$ ) on Mueller-Hinton agar (MHA) containing $5 \%$ sheep blood according to the Kirby-Bauer method (disk diffusion) and the CLSI criteria. An inoculum was ready by suspending 4 -5 freshly grown GBS colonies in 3-5 ml sterile physiological saline. The turbidity was adjusted to a 0.5 McFarland standard [20, 21] used as a reference to adjust the bacterial suspension for antibiotic susceptibility test. The suspension was then swabbed over the entire surface of the Muller Hinton agar containing 5\% defibrinated sheep blood by using sterile cotton tip applicator. Antibiotics disks were placed in the plate and incubated in $5 \% \mathrm{CO}_{2}$ atmosphere at $37{ }^{\circ} \mathrm{C}$ for 24 hours. Zone of inhibition around antibiotic disks was measured by calibrated ruler and interpreted as sensitive, intermediate or resistant by comparing it with the standard chart [20].

\section{Double disc diffusion}

Clindamycin and erythromycin susceptibility tests and determination of different phenotypes of macrolidelincosamide-streptogramin $\mathrm{B}\left(\mathrm{MLS}_{\mathrm{B}}\right)$ resistance were performed by the double-disk test on Mueller-Hinton agar (Biokar, France) containing 5\% sheep blood as previously described [20, 22-24]. Erythromycin (15 $\mu \mathrm{g})$ and 
clindamycin $(2 \mu \mathrm{g})$ disks (Oxoid, UK) were placed $12 \mathrm{~mm}$ apart edge to edge [20]. After 24 hours of incubation at $37^{\circ} \mathrm{C}$, blunting of the clindamycin inhibition zone proximal to the erythromycin disk was taken as inducible clindamycin resistance. Constitutive clindamycin resistance was the resistance to both clindamycin and erythromycin without blunting of the clindamycin inhibition zone. Susceptibility to clindamycin but resistance to erythromycin without blunting of the inhibition zone around the clindamycin disk was the efflux mechanism (the M-phenotype). Eventually, resistance to clindamycin but susceptible to erythromycin was referred to as L phenotype as previously described $[24,25]$.

\section{Quality control}

Half day training was given to the data collectors and they were closely supervised during data collection. Pre-test was done before the actual work to check the protocol for isolation of GBS and the questionnaire for collection of demography and clinical factors of the study participants. Data cleaning were done daily. Streptococcus agalactiae (ATCC 12386), Enterococcus faecalis (ATCC 29212); Streptococcus pyogenes (ATCC 19615), Staphylococcus aureus (ATCC 29213) and Escherichia coli (ATCC 25922) were used as quality control throughout the study.

\section{Data analysis and interpretation}

A total of 385 newborns were enrolled in the study and the collected data were entered into excel spread sheet and exported to SPSS 20 (Chicago, IL, USA) and analyzed. Association between the outcome variable (colonization of newborns with GBS) and each independent variable (demography and clinical factors) was analyzed using bi-variable and multi-variable logistic regression model. All the variables were entered into the multivariable logistic regression using backward LR method to control the confounding effect. Explanatory variables which had significant association with the newborn GBS colonization at a $p$-value $\leq 0.2$ in the bivariable binary logistic regression model were entered to the multivariable logistic regression model to identify the factors associated to the colonization of newborns with GBS. Association between the outcome and the independent variables was calculated by using the adjusted odds ratio at a $p$-value $\leq 0.05$ and $95 \%$ confidence interval. Assumption of goodness of the model was checked by Hosmer-lemeshow test $(p=0.828)$.

\section{Ethical considerations}

The study was reviewed and approved by the Ethical Review Committees of the University of Gondar (IRB) before data collection. Permission was obtained from the Hospitals administrative bodies. The study participants were informed about the study before collecting any data or samples. Written informed consent and/or assent obtained from the study participants. Ear, nasal and umbilical swabs were collected by experienced midwives and processed in the bacteriology laboratory using conventional methods. Participants (mothers) had full right to continue or withdraw their newborns from the study. Confidentiality of all participants' information was maintained throughout the study.

\section{Results \\ Demographic, obstetric characteristics and Group B Streptococcus colonization of newborns}

As shown in Table 1, among the total of 385 newborns tested, $56.1 \%$ were males, $99.2 \%$ were delivered at $>37$ gestational weeks of pregnancy, $89.6 \%$ newborns were weighed $2.5 \mathrm{~kg}$ or more, and $82.1 \%$ of the newborn were delivered within 12 hours of labor. Most of the newborns' mothers $(74.3 \%)$ were housewives and $35.6 \%$ of the mothers had secondary educational status followed by primary school level (34\%).

A total of 1,155 swabs from three body surface sites were collected and 81 (7.0\%) of the specimens were positive for GBS. Among the newborns participated in this study, 62 (16.1\%; 95\% CI: 12.2-20.0) newborns were colonized with GBS and $56.5 \%$ of the GBS positive newborns were males. Among the newborns positive for GBS, $77.1 \%$ were delivered from those mothers whose age was $<25$ years old.

A multivariable logistic analysis indicated that the newborns who were born to mothers whose educational status was below tertiary level; none (AOR $=4.800,95 \%$ CI: $2.752,8.372)$, primary (AOR $=8.371,95 \%$ CI: 4.701 , 14.909), and secondary (AOR $=2.928,95 \% \mathrm{CI}: 1.851$, 4.630); were associated with an increased risk of colonization of newborns with GBS. Some of the maternal factors such as being employed $(\mathrm{AOR}=2.244$, CI: $1.162,4.331)$, being nullipara $(\mathrm{AOR}=3.641,95 \% \mathrm{CI}$ : $2.320,5.714)$ and being multigravida $(\mathrm{AOR}=3.507$, 95\% CI: $2.296,5.355$ ) were also at risk for newborn colonization with GBS. Moreover, we found that two neonatal factors, for instance, newborns who were in need of resuscitation $(\mathrm{AOR}=3.982,95 \% \mathrm{CI}: 1.113$, 14.239) and those newborns who did not have immediate contact (baby not with the mother soon following delivery or baby in the neonatal intensive care unit) with their mothers $(\mathrm{AOR}=4.219,95 \% \mathrm{CI}: 3.058,5.823)$ were associated with increased risk of newborns being colonized with GBS (Table 1).

\section{Colonization of newborns with Group B Streptococcus by the body surface sites}

As noted above, $16.1 \%$ of the total newborns tested in this study were GBS colonized and of the total swabs processed, 81/1,155 (7.01\%) were positive for GBS. 
Table 1 Newborns GBS colonization by demographic and obstetrics characteristics including multivariable analysis, Northwest Ethiopia

\begin{tabular}{|c|c|c|c|c|c|c|}
\hline Characteristics & Response & GBS+ & GBS- & $\mathrm{COR}^{\mathrm{a}} ; 95 \% \mathrm{Cl}$ & $\mathrm{AOR}^{\mathrm{b}}, 95 \% \mathrm{Cl}^{\mathrm{c}}$ & $p$-value \\
\hline \multirow[t]{2}{*}{ Maternal age (yrs) Median $=25$} & $<25$ & 48 & 249 & 1 & - & - \\
\hline & $\geq 25$ & 14 & 74 & $1.019(0.532,1.951)$ & - & - \\
\hline \multirow[t]{2}{*}{ Maternal Residence } & Urban & 51 & 268 & 1 & - & - \\
\hline & Rural & 11 & 55 & $0.951(0.466,1.942)$ & - & - \\
\hline \multirow[t]{4}{*}{ Maternal education } & None & 15 & 72 & $1.200(0.418,3.441)$ & $4.800(2.752,8.372)$ & 0.000004 \\
\hline & Primary & 13 & 118 & $2.269(0.784,6.565)$ & $8.371(4.701,14.909)$ & 0.000004 \\
\hline & Secondary & 28 & 109 & $0.976(0.363,2.609)$ & $2.928(1.851,4.630)$ & 0.000004 \\
\hline & Tertiary & 6 & 24 & 1 & 1 & \\
\hline \multirow[t]{3}{*}{ Maternal occupation } & House wife & 46 & 240 & 1 & 1 & \\
\hline & Employed & 13 & 61 & $0.899(0.457,1.769)$ & $2.244(1.162,4.331)$ & 0.016 \\
\hline & Others & 3 & 22 & $1.406(0.404,4.890)$ & $2.102(0.587,7.530)$ & 0.254 \\
\hline \multirow[t]{2}{*}{ Gestational Age } & $<37 w k s$ & 1 & 2 & $0.681(0.061,7.590)$ & NA & NA \\
\hline & $>/=37 \mathrm{wks}$ & 61 & 321 & 1 & NA & NA \\
\hline \multirow[t]{2}{*}{ Parity } & multipara & 32 & 164 & 1 & 1 & \\
\hline & nulipara & 30 & 159 & $0.967(0.561,1.666)$ & $3.641(2.320,5.714)$ & 0.000 \\
\hline \multirow[t]{2}{*}{ History of still birth } & No & 59 & 308 & 1 & - & - \\
\hline & Yes & 3 & 15 & $0.958(0.269,3.412)$ & - & - \\
\hline \multirow[t]{2}{*}{ History of abortion } & No & 58 & 294 & 1 & - & - \\
\hline & Yes & 4 & 29 & $1.430(0.484,4.223)$ & - & - \\
\hline \multirow[t]{2}{*}{ History of neonatal death } & No & 60 & 316 & 1 & - & - \\
\hline & Yes & 2 & 7 & $0.665(0.135,3.277)$ & - & - \\
\hline \multirow[t]{2}{*}{ Gravidity } & Primigravida & 28 & 156 & 1 & 1 & \\
\hline & Multigravida & 34 & 167 & $0.882(0.511,1.522)$ & $3.507(2.296,5.355)$ & 0.000 \\
\hline \multirow[t]{2}{*}{ ANC visit } & $0-3$ & 16 & 108 & $1.444(0.782,2.669)$ & - & - \\
\hline & $4-5$ & 46 & 215 & 1 & - & - \\
\hline \multirow[t]{2}{*}{ Contraceptive use } & No & 7 & 61 & 1 & - & - \\
\hline & Yes & 55 & 262 & $0.547(0.237,1.259)$ & - & - \\
\hline \multirow[t]{2}{*}{ History of preterm delivery } & No & 60 & 317 & 1 & - & - \\
\hline & Yes & 2 & 4 & $0.379(0.068,2.113)$ & - & - \\
\hline \multirow[t]{2}{*}{ Length of Premature ROM } & $\leq 1 \mathrm{hr}$ & 48 & 223 & 1 & - & - \\
\hline & $>1 \mathrm{hr}$ & 14 & 100 & $1.537(0.810,2.917)$ & - & - \\
\hline \multirow[t]{2}{*}{ HIV status } & No & 59 & 313 & 1 & - & - \\
\hline & Yes & 3 & 10 & $0.628(0.168,2.352)$ & - & - \\
\hline \multirow[t]{2}{*}{ Sex of newborn } & Male & 35 & 181 & $0.983(0.568,1.701)$ & - & - \\
\hline & Female & 27 & 142 & 1 & - & - \\
\hline \multirow[t]{2}{*}{ APGAR $^{d}$ Score at 1 minute } & $<7$ & 5 & 50 & $2.088(0.797,5.467)$ & - & - \\
\hline & $7-10$ & 57 & 273 & 1 & - & - \\
\hline \multirow[t]{2}{*}{ APGAR Score at 5 minutes } & $<7$ & 2 & 28 & $2.847(0.661,12.275)$ & - & - \\
\hline & $7-10$ & 60 & 295 & 1 & - & - \\
\hline \multirow[t]{3}{*}{ Newborn`s weight $(\mathrm{Kg})$ median $=3.0$} & $<2.5$ & 6 & 34 & $1.098(0.440,2.738)$ & - & - \\
\hline & $\geq 2.5$ & 56 & 289 & 1 & - & - \\
\hline & Yes & 16 & 307 & 1 & - & - \\
\hline \multirow[t]{2}{*}{ Resuscitation required } & No & 58 & 287 & 1 & 1 & \\
\hline & Yes & 4 & 36 & $1.819(0.623,5.307)$ & $3.982(1.113,14.239)$ & 0.034 \\
\hline
\end{tabular}


Table 1 Newborns GBS colonization by demographic and obstetrics characteristics including multivariable analysis, Northwest Ethiopia (Continued)

\begin{tabular}{lllllll}
\hline Characteristics & Response & GBS + & GBS- & COR $^{\mathrm{a}} ; 95 \% \mathrm{Cl}$ & $\mathrm{AOR}^{\mathrm{b}}, 95 \% \mathrm{Cl}^{\mathrm{c}}$ & $p$-value \\
\hline Newborn to mother immediate close contact & No & 12 & 76 & $1.282(0.649,2.532)$ & $4.219(3.058,5.823)$ & 0.000 \\
& Yes & 50 & 247 & 1 & 1 & - \\
Duration of labor(hour) & $4-12$ & 54 & 262 & 1 & - & - \\
\hline
\end{tabular}

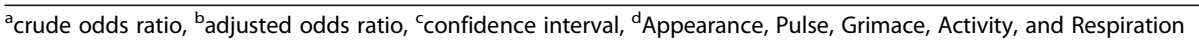

Among the three newborn body surface sites swabbed, the nasal swabs accounted for more $(8.1 \%$, 95\% CI: 5.2-11.3) colonization followed by the umbilical surface swabs (7.5\%, 95\% CI: 5.1-10.6). Fourteen (22.6\%) of the newborns colonized with GBS in this study had more than one body surface site colonization, and $8.1 \%$ had three body surface site GBS colonization (Table 2).

\section{Antibiotic susceptibility patterns of Group B Streptococcus isolates}

All the isolates were tested for 10 commonly prescribed antibiotics by using the recommended methods. Of the GBS identified from the different body surface sites of the newborns, the antibiotics susceptibility ratess (an average of the three body sites tested) were $95.1 \%$, $89.6 \%, 88.9 \%, 85.7 \%, 85.3 \%$, 81.3\%, 76.9\%, 76.1\%, 73.8\%, and $34.4 \%$ to ampicillin, penicillin, ciprofloxacin, chloramphenicol, vancomycin, azitromycin, erythromycin, clindamycin, ceftriaxone, and tetracycline respectively (Table 3 ). The least susceptibility rate (average of the three body surface sites) was reported in tetracycline (34.3\%). Ciprofloxacin, chloramphenicol, vancomycin and azithromycin were found to be the drug of choice next to ampicillin and penicillin in our study.

Table 2 Newborns GBS* colonization by their body surface sites, Northwest Ethiopia $(n=62)$

\begin{tabular}{lll}
\hline Newborn body site colonized & No. of GBS positive & Percentage (\%) \\
\hline Nasal swab $^{a}$ & 31 & 8.1 \\
Ear swab $^{\mathrm{a}}$ & 21 & 5.5 \\
Umbilicus swab $^{\mathrm{a}}$ & 29 & 7.5 \\
Total & 62 & 16.1 \\
Nasal swab only & 19 & 30.6 \\
Ear swab only & 14 & 22.6 \\
Umbilicus swab only & 15 & 24.2 \\
Nasal and ear swabs & 0 & 0.0 \\
Nasal and umbilicus swabs & 7 & 11.3 \\
Ear and umbilicus swabs & 2 & 3.2 \\
Nasal , ear and umbilicus & 5 & 8.1 \\
Total & 62 & 100.0
\end{tabular}

*Group B Streptococcus/Streptococcus agalactiae, ${ }^{a}$ overall prevalence (62; 16.1\%) without combining body sites
Inducible and constitutive resistance Group B Streptococcus isolates to clindamycin

The phenotypic analysis of GBS isolates identified from the three body surfaces sites of the newborns was done by using erythromycin and clindamycin double disc diffusion (D-zone testing) method as per the CLSI 2017 guideline. Among the $32 \mathrm{GBS}$ isolates resistant and/or intermediate resistant to erythromycin and clindmaycin, $34.4 \%$ harboured L phenotype, $31.3 \%$ had $\mathrm{M}$ phenotype, $21.9 \%$ had constitutive Macrolide, LincosamideStreptogramin (B) (cMLSB) and 12.5\% contained inducible Macrolide, Lincosamide-StreptograminB (iMLSB) (Fig. 1 Legend, and Table 4). We found 12.5\% inducible and 21.9\% constitutive resistance GBS to clindamycin.

\section{Discussion}

Our study showed that 62 (16.1\%; 95\% CI: 12.2-20.0) of the newborns participated in the study were colonized with GBS, which could be the possible causes to the high morbidity and mortality of neonates in the study area. This prevalence of colonization was in agreement with different studies conducted worldwide such as: France (13.9\%) [26], Turkey (17.3\%) [27]), South Africa (15.8\%) [14] and Gambia (12.0\%) [28]. Contrary to our study, other studies showed the lower prevalence of newborn colonization with GBS and some of these were Iran $(1.7 \%$ to $5.5 \%)$ [29-31], Saudi Arabia (1.0\%) [32], Turkey $(1.6 \%$ to $8.0 \%)$ [12, 33], Pakistan (6.0\%) [13], China (4.9\%) [34], India (1.3\% to $3.2 \%)$ [35, 36], Korea (1.5\%) [37], Bangladesh (6.3\% to $7.4 \%$; in which, the finding from umbilicus is in agreement with ours) [38, 39], Lithuania (6.4\%; where 5.3\% GBS were isolated from the ear swab of the newborns as it was observed in our study and 4.6\% from the throat) [40], Greek (2.4\%) [41], Nigeria (6.8\%) [42], Tanzania (8.9\%) [43] and Ethiopia (5\%) [19]. The discrepancies might be associated with the Global variability of maternal colonization with GBS (differences in geography, season, IAP provision), the mode of delivery (in which newborns born by spontaneous vaginal delivery had usually more GBS colonization), and the availability of laboratory facilities and experiences of laboratories to detect GBS.

Inconsistent to our result, a lot of studies showed higher neonatal colonization with GBS, for example, studies in 
Table 3 Antibiotic susceptibility patterns of GBS isolated from the newborns` body surfaces, Northwest Ethiopia

\begin{tabular}{|c|c|c|c|c|c|}
\hline \multirow[t]{2}{*}{ Antibiotics } & \multirow[t]{2}{*}{ Disc potency } & \multirow[b]{2}{*}{ Newborn's body sites } & \multicolumn{3}{|c|}{ Colonizing GBS isolates } \\
\hline & & & Susceptible, n(\%) & Intermediate, n(\%) & Resistant, $\mathrm{n}(\%)$ \\
\hline \multirow[t]{3}{*}{ Penicillin } & \multirow[t]{3}{*}{ 10units } & Nasal nare $(n=31)$ & $29(93.5)$ & $0(0.0)$ & $2(6.5)$ \\
\hline & & Umbilicus ( $n=29$ ) & $26(89.7)$ & $0(0.0)$ & $3(10.3)$ \\
\hline & & $\operatorname{Ear}(n=21)$ & $18(85.7)$ & $0(0.0)$ & $3(14.3)$ \\
\hline \multirow[t]{3}{*}{ Ampicillin } & \multirow[t]{3}{*}{$10 \mu \mathrm{g}$} & Nasal nare $(n=31)$ & $29(93.5)$ & $0(0.0)$ & $2(6.5)$ \\
\hline & & Umbilicus ( $n=29$ ) & $28(96.6)$ & $0(0.0)$ & $1(3.4)$ \\
\hline & & $\operatorname{Ear}(n=21)$ & $20(95.2)$ & $0(0.0)$ & $1(4.8)$ \\
\hline \multirow[t]{3}{*}{ Erythromycin } & \multirow[t]{3}{*}{$15 \mu \mathrm{g}$} & Nasal nare $(n=31)$ & $24(77.4)$ & $2(6.5)$ & $5(16.1)$ \\
\hline & & Umbilicus ( $n=29$ ) & $21(72.4)$ & $1(3.4)$ & $7(24.2)$ \\
\hline & & $\operatorname{Ear}(n=21)$ & $17(80.9)$ & $0(0.0)$ & $4(19.1)$ \\
\hline \multirow[t]{3}{*}{ Clindamycin } & \multirow[t]{3}{*}{$2 \mu \mathrm{g}$} & Nasal nare $(n=31)$ & $24(77.4)$ & $1(3.2)$ & $6(19.4)^{a}$ \\
\hline & & Umbilicus ( $n=29$ ) & $22(75.9)$ & $2(6.9)$ & $5(17.2)^{a}$ \\
\hline & & Ear $(n=21)$ & $16(76.2)$ & $2(9.5)$ & $3(14.3)^{a}$ \\
\hline \multirow[t]{3}{*}{ Azitromycin } & \multirow[t]{3}{*}{$15 \mu \mathrm{g}$} & Nasal nare $(n=31)$ & $27(87.1)$ & $1(3.2)$ & $3(9.7)$ \\
\hline & & Umbilicus ( $n=29$ ) & $22(75.9)$ & $4(13.8)$ & $3(10.3)$ \\
\hline & & $\operatorname{Ear}(n=21)$ & $17(80.9)$ & $3(14.3)$ & $1(4.8)$ \\
\hline \multirow[t]{3}{*}{ Vancomycin } & \multirow[t]{3}{*}{$30 \mu \mathrm{g}$} & Nasal nare $(n=31)$ & $26(83.9)$ & $0(0.0)$ & $5(16.1)$ \\
\hline & & Umbilicus ( $n=29$ ) & $25(86.2)$ & $0(0.0)$ & $4(13.8)$ \\
\hline & & $\operatorname{Ear}(n=21)$ & $18(85.7)$ & $0(0.0)$ & $3(14.3)$ \\
\hline \multirow[t]{3}{*}{ Ceftriazone } & \multirow[t]{3}{*}{$30 \mu \mathrm{g}$} & Nasal nare $(n=31)$ & $23(74.2)$ & $0(0.0)$ & $8(25.8)$ \\
\hline & & Umbilicus ( $n=29$ ) & $22(75.9)$ & $0(0.0)$ & $7(24.1)$ \\
\hline & & $\operatorname{Ear}(n=21)$ & $15(71.4)$ & $0(0.0)$ & $6(28.6)$ \\
\hline \multirow[t]{3}{*}{ Ciprofloxacin } & \multirow[t]{3}{*}{$5 \mu \mathrm{g}$} & Nasal nare $(n=31)$ & $29(93.5)$ & $0(0.0)$ & $2(6.5)$ \\
\hline & & Umbilicus ( $n=29$ ) & $24(82.8)$ & $0(0.0)$ & $5(17.2)$ \\
\hline & & $\operatorname{Ear}(n=21)$ & $19(90.5)$ & $0(0.0)$ & $2(9.5)$ \\
\hline \multirow[t]{3}{*}{ Chloramphenicol } & \multirow[t]{3}{*}{$30 \mu \mathrm{g}$} & Nasal nare $(n=31)$ & $26(83.9)$ & $3(9.6)$ & $2(6.5)$ \\
\hline & & Umbilicus ( $n=29$ ) & $24(82.8)$ & $3(10.3)$ & $2(6.9)$ \\
\hline & & $\operatorname{Ear}(n=21)$ & 19 (90.4) & $1(4.8)$ & $1(4.8)$ \\
\hline \multirow[t]{3}{*}{ Tetracycline } & \multirow[t]{3}{*}{$30 \mu \mathrm{g}$} & Nasal nare $(n=31)$ & $8(25.8)$ & $3(9.7)$ & $20(64.5)$ \\
\hline & & Umbilicus ( $n=29$ ) & $10(34.5)$ & $3(10.3)$ & $16(55.2)$ \\
\hline & & $\operatorname{Ear}(n=21)$ & $9(42.9)$ & $0(0.0)$ & $12(57.1)$ \\
\hline
\end{tabular}

${ }^{\mathrm{a} E x c l u d i n g}$ the inducible clindamycin resistant isolates (iMLSB)

Poland (26.7\% to $34.5 \%)$ [44, 45] and Bangladesh (38\%) [39]. The regional differences, variability in the sample size, methods employed for GBS detection, availabilities of laboratory facilities, experiences of laboratory technologists, newborn body surface sites swabbed and time of sample collection (soon after birth or later) might be possibly explained the disparities. The differences could also be explained by the presence or absence of the IAP administration, variations of maternal colonization and density of GBS colony and mode of delivery.

In our study, the antibiotics susceptibility rates of GBS were $95.1 \%, 89.6 \%, 88.9 \%, 85.7 \%, 85.3 \%, 81.3 \%$, $76.9 \%, 76.1 \%, 73.8 \%$, and $34.4 \%$ to ampicillin, penicillin, ciprofloxacin, chloramphenicol, vancomycin, azitromycin, erythromycin, clindamycin, ceftriaxone, and tetracycline respectively. We identified that ciprofloxacin, chloramphenicol, vancomycin and azithromycin were the drug of choice next to ampicillin and penicillin. The GBS in the current study showed better sensitivity to azithromycin than erythromycin and clindamycin. Thus, given the recent interest in the azithromycin, it is wise to do more study on this drug and consider it as the alternative prophylaxis for the penicillin allergic laboring mothers to reduce the carriage of GBS in mothers and newborns and then to lower the risk of neonatal diseases beyond the trachoma control.

In agreement with our findings, a study in Egypt showed that $29.4 \%$ of the GBS isolated from the neonates were 


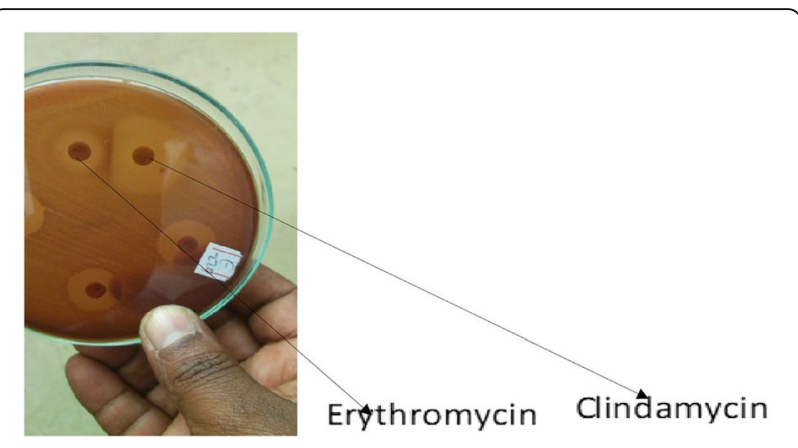

Fig. 1 Inducible Clindamycin resistance (D-zone) of GBS isolated from a newborn ear swab, Northwest Ethiopia. Legend: A S. agalactiae isolated from a newborn ear swab from the University of Gondar referral hospital in Northwest Ethiopia showed Inducible MLS $S_{B}$ phenotype (erythromycin-resistant and clindamycin sensitive) determined by means of an antibiotic disk diffusion test or D-test (the blunting of the clear circular area of no growth around the clindamycin disk on the side adjacent to the erythromycin disk and was designated as D-test positive)

resistance to erythromycin and $17.6 \%$ were resistance to clindamycin [46]. Another studies conducted in different parts of the world such as, in France showed that 25.6\% were resistance to clindamycin and $38.2 \%$ to erythromycin [18] and $21.4 \%$ to macrolide [47], in the USA, $20.2 \%$ to $32 \%$ were resistance to erythromycin and $6.9 \%$ to $15 \%$ to clindamycin $[17,48,49]$, and in Italy, $17 \%$ were resistance to erythromycin and $15.3 \%$ to clindamycin [50]. Another report from Tanzania revealed that the neonatal GBS were $100 \%$ susceptible to penicillin, ampicillin, vancomycin and ciprofloxacin whereas susceptibility to ceftriaxone, clindamycin and erythromycin were 93.8\%, 87.5\% and $81.3 \%$ respectively [43]. A study in Germany also reported that all the isolates were susceptible to beta-lactams and vancomycin while $10.1 \%$ were resistance to erythromycin and $5.7 \%$ to clindamycin [51] which are lower than our reports. This variation might be explained by the fact that the laboratory facilities and health literacy of the people in our setting are different from other developed countries.
Contrasting to the results of our study, a Chinese report revealed that all the GBS isolated from the neonates were susceptible to penicillin, but the rates of resistance to clindamycin and erythromycin were $84.0 \%$ and $88.0 \%$ [52]. These discrepancies may dictate that the rates of resistance to erythromycin and clindamycin varied among geographic regions and were notably the highest in China. Additionally, a study explained that antibiotics currently prevent an estimated 29,000 cases of early onset GBS disease per year. This approach may challenge in the low-income countries where many births take place at home, and laboratory capacity for the screening of GBS is limited [8]. The provision of antibiotics to pregnant women without screening may also contribute to the emergence of antibiotic resistance. An alternative prophylaxis failure is becoming more likely to the increasing of macrolide resistance rates among the GBS isolates. Therefore, in cases when considering these antibiotics, including azithromycin as alternatives for prophylaxis and treatment for GBS, susceptibility test should be done before the prescriptions. We also reported that among the GBS tested for MLS $S_{B}$ by using the double disk diffusion technique, 34.4\%, 31.3\%, 21.9\% and $12.5 \%$ isolates had L- and M- phenotypes, $\mathrm{CMLS}_{\mathrm{B}}$ and $\mathrm{iMLS}_{\mathrm{B}}$, respectively. The inducible and constitutive resistance reported in our study is lower than a study from Canada, where $40.0 \%$ of the isolates were inducible and $47.3 \%$ were constitutive resistance to clindamycin [24].

Of the possible factors associated for the colonization of the newborns that were investigated in our study, the newborns born to mothers whose education status was below tertiary level and from employed mothers had the increased risk of colonization with GBS. It could be justified by the fact that keeping personal hygiene is likely better among those people who have more education status than their counterparts. In addition, employment may increase mobility of women and expose them for different causal partnerships with different people who could be the risks for them, later becomes a source for

Table 4 Macrolide, Lincosamide-StreptograminB (MLSB) and D-shape of the GBS isolates in Northwest Ethiopia

\begin{tabular}{|c|c|c|c|c|c|c|c|c|}
\hline \multicolumn{9}{|l|}{ Double disc diffusion $^{a}$} \\
\hline \multirow[t]{2}{*}{ GBS phenotypes } & \multicolumn{3}{|c|}{ Erythromycin (n) } & \multicolumn{3}{|c|}{ Clindamycin (n) } & \multirow{2}{*}{$\begin{array}{l}\text { Total } \\
(n=32)\end{array}$} & \multirow{2}{*}{$\begin{array}{l}\text { Percent } \\
(\%)\end{array}$} \\
\hline & $\begin{array}{l}\mathrm{R}, \\
</=15 \mathrm{~mm}\end{array}$ & $\begin{array}{l}1,16- \\
20 \mathrm{~mm}\end{array}$ & $\begin{array}{l}\mathrm{S}_{1} \\
>/=21 \mathrm{~mm}\end{array}$ & $\begin{array}{l}R_{1}<1 \\
=15 \mathrm{~mm}\end{array}$ & $\begin{array}{l}1,16- \\
18 \mathrm{~mm}\end{array}$ & $\begin{array}{l}\mathrm{S},>/ \\
=19 \mathrm{~mm}\end{array}$ & & \\
\hline $\begin{array}{l}\text { constitutive macrolide, lincosmide-streptogramin B } \\
\text { (cMLSB) }\end{array}$ & 7 & 0 & - & 6 & 1 & - & 7 & 21.9 \\
\hline $\begin{array}{l}\text { inducible macrolide, lincosmide-streptogramin B } \\
\text { (iMLSB) }\end{array}$ & 4 & 0 & - & 0 & 0 & 4 & 4 & 12.5 \\
\hline M-phenotype & 6 & 4 & - & - & - & 10 & 10 & 31.3 \\
\hline L-Phenotype & - & - & 11 & 7 & 4 & - & 11 & 34.4 \\
\hline D - Shape positive & 4 & 0 & 0 & - & - & 4 & 4 & 12.5 \\
\hline D - Shape negative & - & - & - & - & - & - & 28 & 87.5 \\
\hline
\end{tabular}

${ }^{a} \mathrm{CLSI}$ (2017) disk diffusion breakpoints [57]. For erythromycin: $\geq 21 \mathrm{~mm}$, susceptible (S); 16 to $20 \mathrm{~mm}$, intermediate (I); $\leq 15 \mathrm{~mm}$, resistant (R). For clindamycin: $\geq 19$ $\mathrm{mm}$, susceptible (S); 16 to $18 \mathrm{~mm}$, intermediate (I); $\leq 15 \mathrm{~mm}$, resistant (R) 
their neonatal colonization. Being nulliparity and multigravida are among the maternal factors, and newborns who were in resuscitation and who didn't have immediate contact with their mothers (in the neonatal intensive care unit) had also the increased risk of newborn colonization.

Congruently, different literatures presented that women with less (or no formal,/lack of) education, women of lower parity, multigravid, young maternal age $(<20 \mathrm{yrs})$, vaginal mode of delivery, intrapartum fever, prolonged premature rupture of membrane, preterm gestational age, low birth weight $(<2.5 \mathrm{~kg})$, and neonatal intensive care admission were associated with neonatal colonization with GBS [43, 46, 53-56]. Likewise, a study in Tanzania showed that prolonged duration of labour had the significant association with colonization of the newborns with GBS, possibly due to the extended exposure of the newborns in the birth canal [43]. This calls for the screening of pregnant women for GBS at their 35 to 37 weeks of pregnancy and provision of IAP for those women who have been positive for GBS to reduce the chances of later neonatal colonization.

We found that maternal age, obstetric history, gestational age, sex of the newborn, HIV infection, Appearance, Pulse, Grimace, Activity, and Respiration (APGAR) score, preterm delivery, number of antenatal care (ANC) visit, and duration of labour did not show a significant association with neonatal colonization. In agreement to this, Joachim and his co-workers in Tanzania [43] presented that prolonged premature rupture of membrane, intrapartum fever, mode of delivery and low birth weight did not influence neonatal colonization with GBS. Tsolia et al. [41] in their study reported that the multiparity ( $\geq 2$ previous births) is associated with a low risk for maternal colonization with GBS. It might be explained by the numbers of participants in our study with these risk factors were small. It is useful to know that GBS could be transferred from pregnant women to newborns, and was evidenced by the fact that after the Caesarean section was done (before rupture of the membrane), molecular strain identification demonstrated that same GBS strain was found in mothers and their newborns [45]. So to prevent neonatal colonization with GBS and to increase newborn health conditions, prevention strategies should be developed and promoted in the study area.

\section{Limitations}

This study has main limitations in terms of small sample size, non-probability sampling method, and using only disc diffusion for antibiotic susceptibility test.

\section{Conclusion}

Prevalence of newborn colonization with GBS in this study was higher than the findings reported three Decades ago in the same area. We identified that ciprofloxacin, chloramphenicol, vancomycin and azithromycin were the drug of choice next to ampicillin and penicillin. In addition, $12.5 \%$ of the isolates in our study showed inducible clindamycin resistance. Lower education status, being employed, and being nullipara and multigrapvida were the maternal factors associated with the increased risk of newborn colonization. Resuscitation and denial of the newborn`s immediate contact with their mothers were the neonatal factors which showed the increased risk of newborn colonization. So to prevent neonatal colonization with GBS, continuous health education, screening of pregnancy for GBS at the 35 to 37 weeks of gestation and provision of IAP for those positive cases for GBS should be promoted in the study area. GBS surveillance and their antibiotic susceptibility testing should also be conducted in the country by using advanced laboratory technologies.

\section{Additional file}

Additional file 1: Questionnaire for Newborn colonization with GBS University of Gondar Referral Hospital, Northwest Ethiopia (DOCX 29 kb)

\section{Abbreviations \\ ANC: Antenatal Care; AOR: Adjusted Odds Ratio; APGAR: Appearance, Pulse, Grimace, Activity, and Respiration; ATCC: American Type Culture Collection; CAMP: Christie-Atkins-Munch-Petersen; Cl: Confidence Interval; CLSI: Clinical Laboratory Standard Institute; $\mathrm{CO}_{2}$ : Carbon dioxide; GBS: Group B Streptococcus; HIV: Human Immune deficiency Virus; IAP: Intrapartum Antibiotics Prophylaxis; MLS : Macrolide-Lincosamide-Streptogramin B; PROM: Premature Rupture of Membrane; S. agalactiae: Streptococcus agalactiae; S. aureus: Staphylococcus aureus; SPSS: Statistical Package for Social Sciences; $\mu \mathrm{g} / \mathrm{L}$ : Microgram per liter}

\section{Acknowledgment}

The authors would like to acknowledge the financial and material support from the College of Medicine and Health Sciences, University of Gondar, Northwest Ethiopia, the German Academic Exchange Service (DAAD), Germany, and the Institute of Virology, Leipzig University, Germany. The authors are also grateful to the study participants and data collectors.

\section{Funding}

Financial and material support were from the University of Gondar, Ethiopia, the German Academic Exchange Service (DAAD) In-Country scholarship and the Institute of Virology, Leipzig University, Germany for salary, material procurement, data collection, analysis, and interpretation and in writing the manuscript, printing and copying services.

\section{Availability of data and materials}

The data used and/or analyzed in this article available from the corresponding author on reasonable request.

\section{Authors' contributions}

MG participated in conception and design of the study, acquisition of data, analysis and Interpretation of findings. BT participated in conception and design of the study, and interpretation of data; he also participated in revision of the manuscript. MT participated in design of the study, acquisition and interpretation data; in revision of the manuscript. FM participated in conception of the study; and revision of the manuscript. MA participated in design of the study, and revision of the manuscript. ZT participated in interpretation of data, drafting and revision of the manuscript. All authors read and approved the final manuscript.

Ethics approval and consent to participate

It is done after we secured ethical approval from the institutional review board of the University of Gondar (R.No.ON/P/RCS/05/478/2015 Mega project and O/N/P/RCS/05/471/2018). Permission was obtained from the University of Gondar Referral Hospitals administrative bodies. After giving a 
brief description about the purpose of the study, eligible mothers gave informed written consent for their participation in the questionnaire of this study and for their newborns to be a part of such a study. Confidentiality was ensured using code numbers than names and keeping the data locked

\section{Consent for publication}

Not applicable

\section{Competing interests}

The authors declare that they have no competing interests

\section{Publisher's Note}

Springer Nature remains neutral with regard to jurisdictional claims in published maps and institutional affiliations.

\section{Author details}

'Department of Medical Microbiology, School of Biomedical and Laboratory Sciences, College of Medicine and Health Sciences, University of Gondar, P. O. Box 196, Gondar, Ethiopia. ²Department of Gynecology and Obstetrics, School of Medicine, College of Medicine and Health Sciences, University of Gondar, P. O. Box 196, Gondar, Ethiopia. ${ }^{3}$ Department of Pediatrics, School of Medicine, College of Medicine and Health Sciences, University of Gondar, P. O. Box 196, Gondar, Ethiopia.

\section{Received: 11 May 2018 Accepted: 19 November 2018}

\section{Published online: 30 November 2018}

\section{References}

1. Central Statistical Agency (CSA) [Ethiopia], ICF. Ethiopia Demographic and Health Survey 2016: Key Indicators Report. AAddis Ababa, Ethiopia, and Rockville, Maryland: CSA and ICF; 2016. p. 21-2.

2. Amhara National Regional State Bureau of Health. Health Research Thematic Areas of Amhara Regional Health Bureau: Amhara Regional Health Bureau Health Research and Technology Transfer Core Process in collaboration with Ethiopan Network for HIV/AIDS Treatment Care and Support (ENHAT-CS) Amhara Region Program. First Edition, Bahir dar, Ethiopia. 2013:1- 41.

3. Rick AM, Aguilar A, Cortes R, Gordillo R, Melgar M, Samayoa-Reyes G, et al. Group B Streptococci Colonization in Pregnant Guatemalan Women: Prevalence, Risk Factors, and Vaginal Microbiome. Open Forum Infect Dis. 2017:4(1):ofx020.

4. Chan GJ, Lee ACC, Baqui AH, Tan J, Black RE. Prevalence of early-onset neonatal infection among newborns of mothers with bacterial infection or colonization: a systematic review and meta-analysis. BMC Infect Dis. 2015;15:118.

5. Kulkarni R, Randis TM, Antala S, Wang A, Amaral FE, Ratner AJ. $\beta$-Hemolysin/ Cytolysin of Group B Streptococcus Enhances Host Inflammation but Is Dispensable for Establishment of Urinary Tract Infection. PLoS ONE. 2013;8(3):e59091.

6. Schrag SJ, Zywicki S, Farley MM, Reingold AL, Harrison LH, Lefkowitz LB, et al. Group B streptococcal disease in the era of intrapartum antibiotic prophylaxis. N Engl J Med. 2000a;342(1):15-20.

7. Valkenburg-van den Berg AW, Sprij AJ, Oostvogel PM, Mutsaers JA, Renes $W B$, Rosendaal FR, et al. Prevalence of colonization with group $B$ Streptococci in pregnant women of a multi-ethnic population in The Netherlands. Eur J Obstet Gynecol Reprod Biol. 2006;124(2):178-83.

8. Seale AC, Bianchi-Jassir F, Russell NJ, Kohli-Lynch M, Tann CJ, Hall J, et al. Estimates of the Burden of Group B Streptococcal Disease Worldwide for Pregnant Women, Stillbirths, and Children. Clin Infect Dis. 2017;65(suppl_2): S200-S19.

9. Mohammed M, Asrat D, Woldeamanuel Y, Demissie A. Prevalence of group B Streptococcus colonization among pregnant women attending antenatal clinic of Hawassa Health Center, Hawassa. Ethiopia. Ethiop J Health Dev. 2012;26(1):36-42.

10. Centers for Disease Control and Prevention. Prevention of perinatal group B streptococcal disease: revised guidelines from CDC. MMWR. 2010;59(RR-10): $1-36$.

11. Regan JA, Klebanoff MA, Nugent RP, Eschenbach DA, Blackwelder WC, Lou $Y$, et al. Colonization with group B streptococci in pregnancy and adverse outcome. VIP Study Group Am J Obstet Gynecol. 1996;174(4):1354-60.
12. Eren A, Küçükercan $M$, Oğuzoğlu N, Unal N, Karateke A. The carriage of group B streptococci in Turkish pregnant women and its transmission rate in newborns and serotype distribution. Turk J Pediatr. 2005;47(1):28-33.

13. Chaudhry BY, Akhtar N, Balouch AH. Vaginal carriage rate of Group B Streptococcus in pregnant women and its transmission to neonates. J Ayub Med Coll Abbottabad. 2010;22(4):167-70.

14. Madzivhandila M, Adrian PV, Cutland CL, Kuwanda L, Schrag SJ, Madhi SA. Serotype Distribution and Invasive Potential of Group B Streptococcus Isolates Causing Disease in Infants and Colonizing Maternal-Newborn Dyads. PLoS ONE. 2011;6(3):e17861.

15. Schrag SJ, Whitney CG, Schuchat A. Neonatal group B streptococcal disease: how infection control teams can contribute to prevention efforts. Infect Control Hosp Epidemiol. 2000b;21(7):473-83.

16. Garland SM, Cottrill E, Markowski L, Pearce C, Clifford V, Ndisang D, et al. Antimicrobial resistance in group B streptococcus: the Australian experience. Journal of Medical Microbiology. 2011;60(Pt 2):230-5.

17. Lin FC, Azimi PH, Weisman LE, Philips JB III, Regan J, Clark P, et al. Antibiotic Susceptibility Profiles for Group B Streptococci Isolated from Neonates, 1995-1998. Clinical Infectious Diseases. 2000;31(1):76-9.

18. Hays C, Louis M, Plainvert C, Dmytruk N, Touak G, Trieu-Cuot P, et al. Changing Epidemiology of Group B Streptococcus Susceptibility to Fluoroquinolones and Aminoglycosides in France. Antimicrob Agents Chemother. 2016;60(12):7424-30.

19. Schmidt J, Halle E, Halle H, Mohammed T, Gunther E. Colonization of pregnant women and their newborn infants with group B Streptococci in the Gondar College of Medical Sciences. Ethiop Med J. 1989;27(3):115-9.

20. Clinical Laboratory Standard Institute. Performance Standards for Antimicrobial Susceptibility Testing. 27th ed, CLSI supplement M100 Wayne, PA: Clinical and Laboratory Standards Institute; 2017;37(1):84-87.

21. Bauer AW, Kirby WM, Sherris JC, Turck M. Antibiotic susceptibility testing by a standardized single disk method. Am J Clin Pathol. 1966;45(5):493-6.

22. Seppala $H$, Skurnik M, Soini $H$, Roberts MC, Huovinen P. A novel erythromycin resistance methylase gene (ermTR) in Streptococcus pyogenes. Antimicrob Agents Chemother. 1998;42(2):257-62.

23. Quiroga M, Pegels E, Oviedo P, Pereyra E, Vergara M. Susceptibility patterns and prevalence of GBS isolated from pregnant women in Misiones. Argentina. Braz J Microbiol. 2008;39(2):245-50.

24. Desjardins M, Delgaty KL, Ramotar K, Seetaram C, Toye B. Prevalence and mechanisms of erythromycin resistance in group $A$ and group $B$ streptococcus: implications for reporting susceptibility results. J Clin Microbiol. 2004;42(12):5620-3.

25. Khan AS, Walsh A, Crowleyet B. Role of efflux in macrolide resistance in $\beta$ hemolytic streptococci of groups A, B, C and G collected in an Irish teaching hospital. J Med Microbiol. 2011;60(Pt 2):262-4.

26. Jost $C$, Bercot B, Jacquier $H$, Raskine $L$, Barranger E, Mouchnino $G$, et al. Xpert GBS Assay for Rapid Detection of Group B Streptococcus in Gastric Fluid Samples from Newborns. J Clin Microbiol. 2014;52(2):657-9.

27. Kadanali A, Altoparlak U, Kadanali S. Maternal carriage and neonatal colonisation of group B streptococcus in easternTurkey: prevalence, risk factors and antimicrobial resistance. Int J Clin Pract. 2005;59(4):437-40.

28. Roca A, Bojang A, Camara B, Oluwalana C, Lette K, West P, et al. Maternal colonization with Staphylococcus aureus and Group B streptococcus is associated with colonization in newborns. Clinical Microbiology and Infection. 2017:23(12):974-9.

29. Hamedi A, Akhlaghi F, Seyedi SJ, Kharazmi A. Evaluation of group B Streptococci colonization rate in pregnant women and their newborn. Acta Med Iran. 2012;50(12):805-8.

30. Nahaei MR, Ghandchilar N, Bilan N, Ghahramani P. Maternal carriage and neonatal colonization of Streptococcus agalactiae in Tabriz. Northwest Iran. Iran J Med Sci. 2015;32(3):177-81.

31. Jahromi BN, Poorarian S, Poorbarfehee $\mathrm{S}$. The prevalence and adverse effects of group B streptococcal colonization during pregnancy. Arch Iran Med. 2008;11(6):654-7.

32. Al-Sunaidi M, Al-Shahrani M, Damole IO, Bello CSS. Prevalence of Group B Streptococcus Colonization in Mothers and Babies at Abha General Hospital, Kingdom of Saudi Arabia. Med J Cairo Univ. 2011;79(2):163-5.

33. Barbaros I, Murat C, Mehmet V, Ismet TA, Can K, Sukufe D, et al. The colonization incidence of group $B$ streptococcus in pregnant women and their newborns in Istanbul. Pediatr Int. 2005:47(1):64-6.

34. Yang J, Xu D, Yin LQ, Zhu BQ, Wang AH. Neonatal group B streptococcus infection in the Children's Hospital of Gansu Province through PCR array. Zhonghua Er Ke Zhi. 2013;51(9):688-91. 
35. Kulkarni AA, Pawar SG, Dharmadhikari CA, Kulkarni RD. Colonization of pregnant women and their newborn infants with Group B Streptococci. Indain Journal Medical Microbiology. 2001;19(2):97-100.

36. Shah D, Saxena S, Randhawa VS, Nangia S. Dutta Prospective analysis of risk factors associated with group B streptococcal colonisation in neonates born at a tertiary care centre in India. Paediatr Int Child Health. 2014;34(3):184-8.

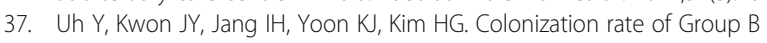
Streptococcus in pregnant women and neonates. Korean J Clin Pathol. 1994;14(4):447-53.

38. Islam MS, Saha SK, Islam M, Modak JK, Shah R, Talukder RR, et al. Prevalence, Serotype Distribution and Mortality Risk Associated With Group B Streptococcus Colonization of Newborns in Rural Bangladesh. Pediatr Infect Dis J. 2016;35(12): 1309-12.

39. Saha SK, Ahmed ZB, Modak JK, Naziat H, Saha S, Uddin MA, et al. Group B Streptococcus among Pregnant Women and Newborns in Mirzapur, Bangladesh: Colonization, Vertical Transmission, and Serotype Distribution. J Clin Microbiol. 2017;55(8):2406-12.

40. Barcaite E, Bartusevicius A, Tameliene R, Maleckiene L, Vitkauskiene A, Nadisauskiene R. Group B streptococcus and Escherichia coli colonization in pregnant women and neonates in Lithuania. Int J Gynaecol Obstet. 2012; 117(1):69-73.

41. Tsolia M, Psoma M, Gavrili S, Petrochilou V, Michalas S, Legakis N, et al. Group B streptococcus colonization of Greek pregnant women and neonates: prevalence, risk factors and serotypes. Clin Microbiol Infect. 2003:9(8):832-8.

42. Elikwu CJ, Oduyebo O, Ogunsola FT, Anorlu Rl, Okoromah CN, König B. High group B streptococcus carriage rates in pregnant women in a tertiary institution in Nigeria. Pan Afr Med J. 2016;25:249.

43. Joachim A, Matee MI, Massawe FA, Lyamuya EF. Maternal and neonatal colonisation of group B streptococcus at Muhimbili National Hospital in Dar es Salaam, Tanzania: prevalence, risk factors and antimicrobial resistance. BMC Public Health. 2009;9:437.

44. Kowalska B, Niemiec KT, Drejewicz H, Polak K, Kubik P, Elmidaoui A, et al. Prevalence of group $B$ streptococcal colonization in pregnant women and their newborns based on the results of examination of patients in the Obstetric and Gynecology Department of the National Research Institute of Mother and Child--a pilot study. Ginekol Pol. 2003;74(10):1223-7.

45. Strus M, Pawlik D, Brzychczy-Włoch M, Gosiewski T, Rytlewski K, Lauterbach $R$, et al. Group B streptococcus colonization of pregnant women and their children observed on obstetric and neonatal wards of the University Hospital in Krakow, Poland. J Med Microbiol. 2009;58(Pt 2):228-33.

46. Sultan AM, Mahfouz RA, Ali MM, Taher S. Virulence Factors of Streptococcus agalactiae in Neonatal Sepsis. Egyptian Journal of Medical Microbiology. 2012;21(2):1-10.

47. Mouy DD, Cavallo J, Leclercq R, Fabre R. The Aforcopi-Bio Network. Antibiotic Susceptibility and Mechanisms of Erythromycin Resistance in Clinical Isolates of Streptococcus agalactiae: French Multicenter Study. Antimicrob Agents Chemother. 2001;45(8):2400-2.

48. Phares CR, Lynfield R, Farley MM, Mohle-Boetani J, Harrison LH, Petit S, et al. Epidemiology of invasive group B streptococcal disease in the United States, 1999-2005. JAMA. 2008;299(17):2056-65.

49. Castor ML, Whitney CG, Como-Sabetti K, Facklam RR, Ferrieri P, Bartkus JM, et al. Antibiotic resistance patterns in invasive group B streptococcal isolates. Infect Dis Obstet Gynecol. 2008;2008:727505.

50. Creti R, Imperi M, Berardi A, Pataracchia M, Recchia S, Alfarone G, et al. Neonatal Group B Streptococcus Infections: Prevention Strategies, Clinical and Microbiologic Characteristics in 7 Years of Surveillance. Pediatr Infect Dis J. 2017;36(3):256-62.

51. Fluegge K, Supper S, Siedler A, Berner R. Antibiotic Susceptibility in Neonatal Invasive Isolates of Streptococcus agalactiae in a 2-Year Nationwide Surveillance Study in Germany. Antimicrob Agents Chemother. 2004;48(11): 4444-6.

52. Dong $Y$, Jiang $S$, Zhou Q, Cao Y. Group B Streptococcus causes severe sepsis in term neonates: 8 years experience of a major Chinese neonata unit. World Journal of Pediatrics. 2017;13(4):314-20.

53. Schuchat A, Zywicki SS, Dinsmoor MJ, Mercer B, Romaguera J, O'Sullivan MJ, et al. Risk factors and opportunities for prevention of early-onset neonatal sepsis: a multicenter case-control study. Pediatrics. 2000;105(1 Pt 1):21-6.

54. Patil KP, Singla SS, Nagmoti MB, Swamy MK. Group B Streptococci Colonization in Pregnant women: is Screening a Necessary? J South Asian Feder Obst Gynae. 2013;5(2):64-7.
55. Regan JA, Klebanoff MA, Nugent RP. The epidemiology of group B streptococcal colonization in pregnancy. Vaginal Infections and Prematurity Study Group. Obstet Gynecol. 1991;77(4):604-10.

56. Orrett FA. Colonization with Group B streptococci in pregnancy and outcome of infected neonates in Trinidad. Pediatr Int. 2003;45(3):319-23.

57. Clinical and Laboratory Standards Institute. Performance Standards for Antimicrobial Susceptibility Testing. 27th ed. CLSI supplement M100. Way n e, PA: Clinical and Laboratory Standards Institute. 2017;37(1):84-7.

\section{Ready to submit your research? Choose BMC and benefit from:}

- fast, convenient online submission

- thorough peer review by experienced researchers in your field

- rapid publication on acceptance

- support for research data, including large and complex data types

- gold Open Access which fosters wider collaboration and increased citations

- maximum visibility for your research: over $100 \mathrm{M}$ website views per year

At BMC, research is always in progress.

Learn more biomedcentral.com/submissions 